\title{
Intra-arterial thrombolysis in acute ischaemic stroke: experience with a superselective catheter embedded in the clot
}

Luciano Casto, Lionello Caverni, Massimo Camerlingo, Bruno Censori, Luca Moschini, Maria Cristina Servalli, Tania Partziguian, Giorgio Belloni, Angelo Mamoli

\begin{abstract}
Objectives-To report experience of intra-arterial thrombolysis for acute stroke, performed with a microcatheter navigated into the intracranial circulation to impale the clot.

Methods-Patients were selected on the following criteria: (1) clinical examination suggesting a large vessel occlusion in stroke patients between 18 and 75 years; (2) no radiographic signs of large actual ischaemia on CT at admission; (3) angiographically documented occlusion of the middle cerebral artery (MCA) stem or of the basilar artery (BA), without occlusion of the ipsilateral extracranial internal carotid artery or of both the vertebral arteries; (4) end of the entire procedure within six hours of stroke. 12 patients with acute stroke were recruited, eight of whom had occlusion of the MCA stem and four of the BA. Urokinase was used as the thrombolytic agent.
\end{abstract}

Results-Complete recanalisation in six MCA stem and in two BA occurred, and partial recanalisation in two MCA stem and one BA. There was no recanalisation in one BA. A clinically silent haemorrhage occurred in two patients, and a parenchymal haematoma in one patient, all in MCA occlusions. At four months five patients achieved self sufficiency (four with MCA and one with BA occlusion). Six patients were dependent (three totally), and one died.

Conclusions-The strict criteria of eligibility allowing the enrolment of very few patients and the procedure itself, requiring particular neuroradiological expertise, make this procedure not routine. Nevertheless, the approach can be considered a possible option for patients with acute ischaemic stroke.

\section{(F Neurol Neurosurg Psychiatry 1996;60:667-670)}

Keywords: acute ischaemic stroke; cerebral arterial occlusion; intra-arterial thrombolysis

To use thrombolysis effectively in acute ischaemic stroke is a major current challenge. Cumulative experiences with intravenous or intra-arterial treatment have shown its feasibility in humans, and suggest an association between recanalisation and clinical improvement. ${ }^{1.3}$ Unfortunately, some clinical trials with intravenous drugs had to be interrupted because of an excess of cerebral haemorrhages, and the conclusions from the European Cooperative Acute Stroke Study (ECASS) ${ }^{4}$ clearly indicate that intravenous thrombolysis is not a treatment for all patients with acute stroke. The intra-arterial approach has recently been improved by the introduction of catheters that can be navigated into the intracranial circulation and are able to disrupt the thrombus with the tip before delivering drugs. We report 12 patients treated with this approach.

\section{Patients and methods}

From January 1991 to February 1995, after previous experience with a local intra-arterial approach, ${ }^{5}$ we have considered patients presenting within four hours of a severe acute ischaemic stroke for mechanical disruption of the thrombus and intra-arterial delivery of the thrombolytic agent. Exclusion criteria were: (1) inability to end the entire procedure within six hours of the onset of stroke; (2) occlusion of the extracranial arteries ipsilateral to stroke in patients with hemispheric stroke or of both vertebral arteries in cases of brainstem stroke; (3) direct or indirect signs of large actual ongoing infarction or of any disease other than stroke on CT at admission; (4) age $<18$ or $>75$ years; (5) regression of signs before starting the procedure; (6) any contraindication for thrombolytic agents; (7) severe systolic hypertension $(>180 \mathrm{~mm} \mathrm{Hg}$ ) despite appropriate treatment; (8) severe concurrent diseases interfering with natural life expectancy; (9) absence of informed consent from patients or relatives. Indirect signs of pronounced ischaemia of middle cerebral artery territories were effacement of most sulci, diffuse swelling, early parenchymal hypodensity, and loss of putaminal hyperdensity. The protocol was approved by our ethics committee. Patients who were selected were submitted to arteriography with the Seldinger method, utilising a digital subtraction device (TG 200, CER, Paris, France). Topographic localisation of the occluded segments of the middle cerebral artery was adapted from Boazzao et $a l^{6}$ (M1 = the mainstem of the middle cerebral artery before the lenticular arteries, $M 2=$ the mainstem after the lenticular arteries, and M3 $=$ the bifurcation of the mainstem). Once appropriate occlusion of the middle cerebral artery stem or of the basilar artery was demonstrated, a microcatheter (Tracker 18, Target Therapeutics, San Jose, CA) was mounted on the guidewire, and pushed onwards to impale, 
Figure 1 Patient 2: (A) pretreatment $M 1$ occlusion. (B) The tip of the catheter is beyond the thrombus with opacification of the distal vessels. (C) Post-treatment recanalisation with possible embolisation in some distal parietal branches.

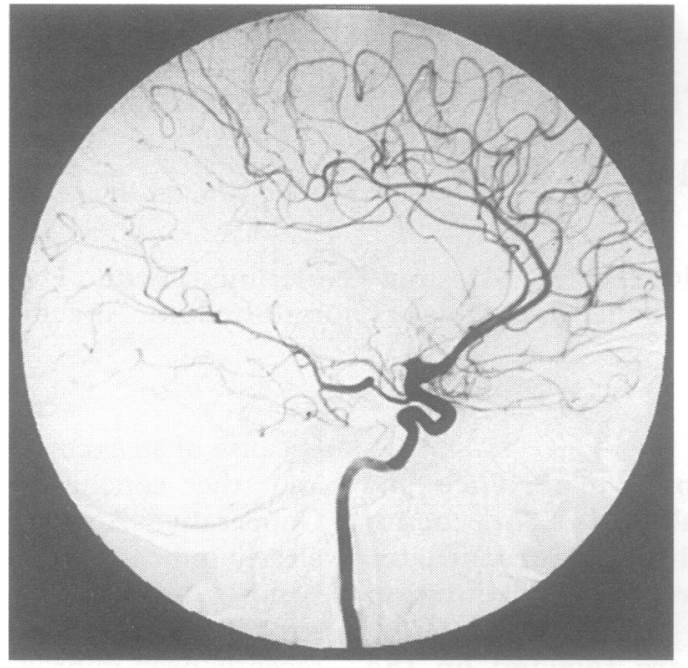

A

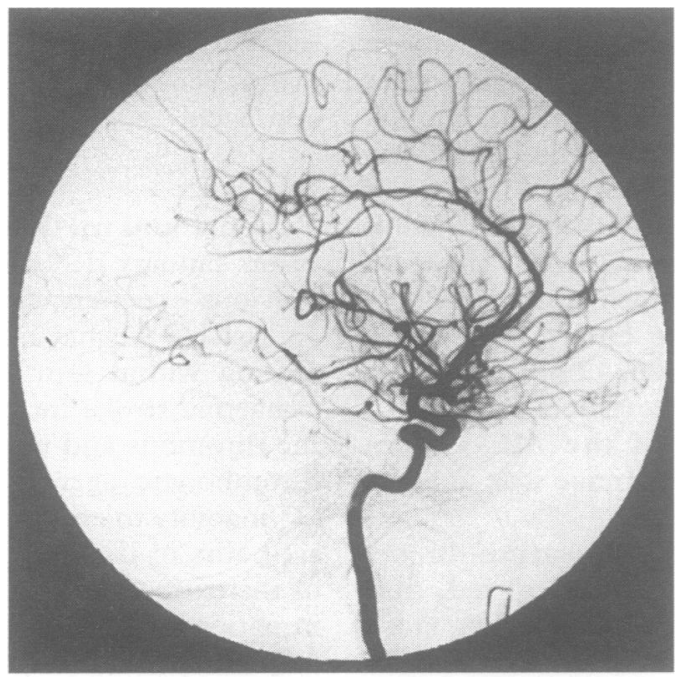

C

and pass through, the clot. After showing the patency of the circulation beyond the clot, urokinase was delivered. We used urokinase, because it was the thrombolytic agent allowed for intra-arterial delivery in our hospital. We used a bolus of 100000 units, followed by a pump infused dose of 500000 units over one hour. In cases of persistent arterial occlusion urokinase was added to a total of 1000000 units. Recanalisation was defined as absent,

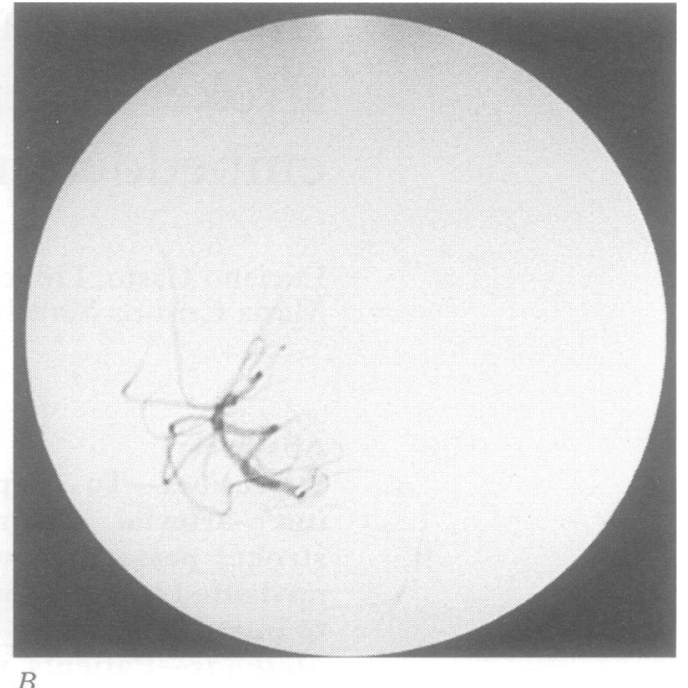

partial, or complete. Patients were then closely monitored in our stroke unit, for bleeding and other complications. Subcutaneous calcium heparin (12 500 units twice a day), was started 30 minutes after the end of the procedure and continued until oral anticoagulation or antiplatelet treatment was initiated. Brain CT was carried out on admission, within seven days of treatment, and whenever clinically required. Neurological examination was carried out on admission, immediately after the treatment, daily for seven days, and at one and four months after treatment and scored with the National Institute for Health Scale. ${ }^{7}$ Outcome was assessed with a modified Rankin score scale at four months. ${ }^{8}$ A score 1-2 was deemed self sufficiency, 3 partial dependency, 4 and 5 total dependency, and 6 death.

\section{Results}

A total of 1342 stroke patients were admitted in our ward over the study period. The eligibility criteria immediately ruled out 603 patients as outside the age limits. Of the others, 162 were seen within four hours and 18 of them underwent angiography. Three already had patent intracranial circulation and three had an extended occlusion of the extracranial internal carotid artery and siphon. Twelve patients were eventually treated (five women

Clinical characteristics: time to treatment, dose of urokinase, recanalisation, haemorrhagic transformations, and outcome at four months

\begin{tabular}{|c|c|c|c|c|c|c|c|c|c|}
\hline & Age/sex & Signs & Risk factors & $\begin{array}{l}\text { Occlusion } \\
\text { site }\end{array}$ & $\begin{array}{l}\text { Time } \\
\text { (min) }\end{array}$ & $U K(M U)$ & $\operatorname{Rec}$ & Haem & Rankin \\
\hline 1 & $27 / F$ & LH & Pill & M2 & 120 & 0.6 & $\mathrm{~T}$ & HT & 1 \\
\hline 2 & $31 / F$ & $\mathrm{LH}$ & VAF & M1 & 120 & $0 \cdot 6$ & $\mathrm{~T}$ & - & 2 \\
\hline 3 & $33 / \mathrm{F}$ & LH & MVD & M1 & 130 & $0 \cdot 7$ & $\mathrm{~T}$ & - & 2 \\
\hline 4 & $35 / \mathrm{M}$ & $\mathrm{TP} / \mathrm{S}$ & Нyp & BA & 180 & $0 \cdot 8$ & $\mathrm{~T}$ & - & 2 \\
\hline 5 & $44 / M$ & $\mathrm{TP} / \mathrm{S}$ & None & BA & 120 & $1 \cdot 0$ & No & - & 5 \\
\hline 6 & $50 / \mathrm{M}$ & $\mathrm{TP} / \mathrm{S}$ & None & BA & 120 & $0 \cdot 7$ & $\mathrm{~T}$ & - & 3 \\
\hline 7 & $53 / \mathrm{M}$ & RH/A & $\mathrm{Sm}$ & M3 & 120 & $0 \cdot 8$ & $\mathbf{P}$ & - & 3 \\
\hline 8 & 58/M & LH & MVD & M1 & 300 & $0 \cdot 8$ & $\mathrm{~T}$ & - & 4 \\
\hline 9 & $68 / \mathrm{F}$ & LH & AF & M3 & 180 & $0 \cdot 8$ & $T$ & - & 2 \\
\hline 10 & $68 / \mathrm{F}$ & LH & $\mathrm{AF} / \mathrm{Sm} / \mathrm{Hyp}$ & M1 & 120 & $0 \cdot 7$ & $\mathrm{~T}$ & PHE & 4 \\
\hline 11 & 69/M & TP/S & Нyp & BA & 120 & $1 \cdot 0$ & $\mathbf{P}$ & - & 6 \\
\hline 12 & $72 / \mathrm{M}$ & RH/A & $\mathrm{AF}$ & M3 & 300 & $0 \cdot 8$ & $\mathbf{P}$ & HT & 3 \\
\hline
\end{tabular}

LH = Left hemiplegia; $R H=$ right haemiplegia; $A=$ aphasia; $T P / S=$ tetraparesis and stupor; $M V D=$ mitral valve disease; VAF = valvar atrial fibrillation; $\mathrm{Sm}=$ smoking, $\mathrm{AF}=$ atrial fibrillation; hyp = hypertension; $\mathrm{M1} ; 2 ; 3$, see text; $\mathrm{BA}=$ basilar artery occlusion Time = time from stroke to treatment; UK = urokinase; $M U=$ MegaUnits; Rec = recanalisation; $T=$ total; $P=$ partial; Haem brain haemorrhage; $\mathrm{HT}=$ haemorrhagic transformation; $\mathrm{PHE}=$ parenchymal haematoma. 
Figure 2 Patient 4: (A) pretreatment occlusion of the distal basilar artery. (B) The microcatheter tip (arrows) is beyond the thrombus, which is clearly visible (arrowhead). (C) Post-treatment thrombus dissolution with embolisation in the left posterior cerebral artery.

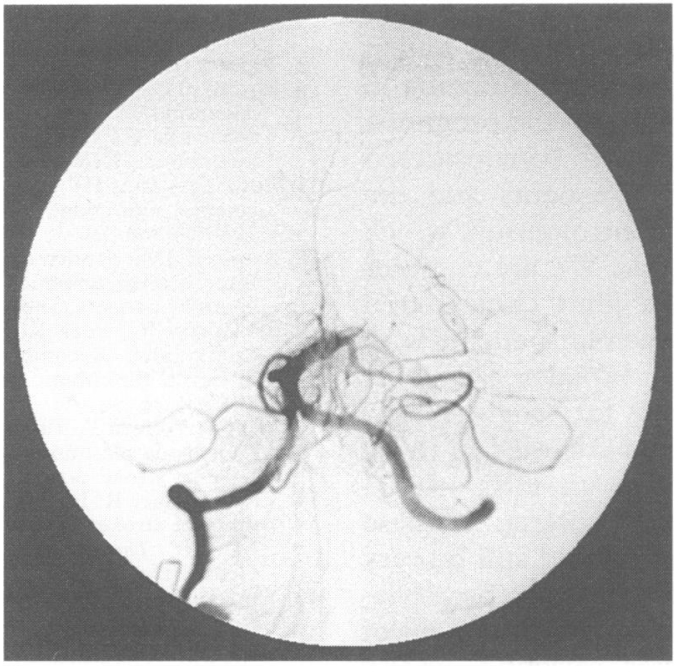

A

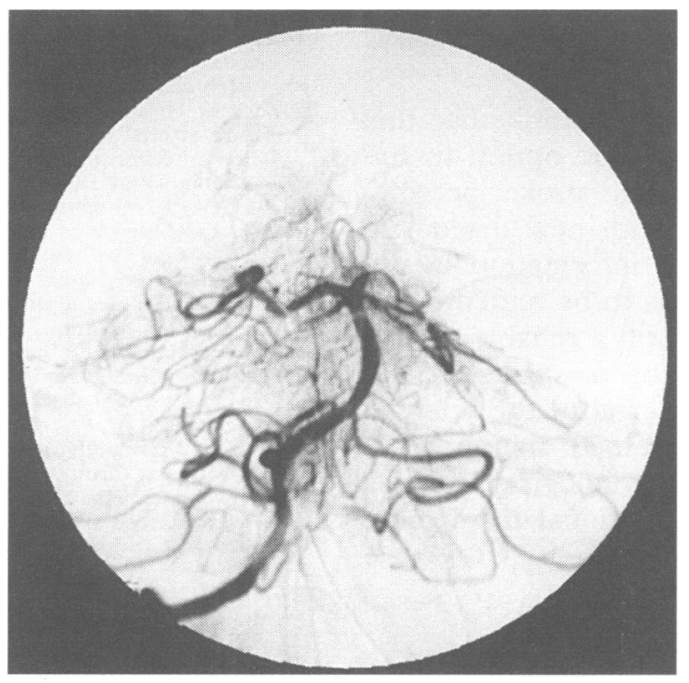

C

and seven men, aged 27 to 72 years). Six of them had potential cardiac sources of emobolism, and two were free from risk factors for stroke. The clinical picture of stroke was: a left hemiplegia plus hemianopia and hemineglect in six patients, a right hemiplegia plus aphasia and hemianopia in two, tetraparesis and stupor in four. Arteriography showed arterial occlusion at the $M 1$ segment in four patients, at M2 in one, at M3 in three, and in the basilar trunk in four. Recanalisation was achieved in 11 patients. It was complete in eight and partial in three. Haemorrhage was seen in three patients: in two it was clinically silent, in one it was accompanied by clinical deterioration with $\mathrm{CT}$ features of parenchymal haematoma. It always occurred in the stroke territories. None of the patients had systemic haemorrhages. After four months five patients (four with middle cerebral artery and one with basilar artery occlusion) regained self sufficiency, three were partially dependent, and three were totally dependent. One patient died 14 days after stroke because of reocclusion of a partially reopened basilar artery, after dramatic temporary improvement. The table gives the results.

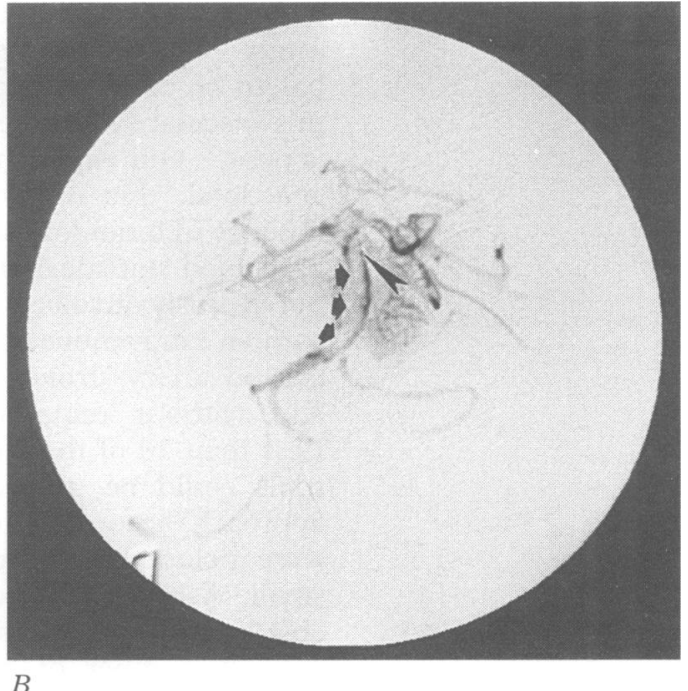

Discussion

Our experience suggests that intra-arterial thrombolysis with a microcatheter brought up to impale the clot can be beneficial for patients with acute stroke from middle cerebral artery stem or basilar artery occlusion, but it cannot be considered as a routine approach. This technique is associated with a higher rate of arterial recanalisation than the intravenous approach. ${ }^{1}$ Recanalisation, which is a requirement of efficacy, ${ }^{9-19}$ seems related to location and nature of the occlusion; the extracranial portions of the internal carotid artery were less amenable to recanalisation than the distal ones. ${ }^{20-22}$ The rationale of this technique is supported by the concept that the mechanical disruption of the clot would increase the area of contact with the drug, mimimising the risks of local and systemic bleeding. Eight patients improved and five patients regained total selfsufficiency. Our results are in agreement with the report of a recent revision of published experiences with intra-arterial thrombolysis as far as recanalisation and outcome are concerned. ${ }^{23}$ Bollaert et al, using the same procedure, reported more deaths and poorer outcomes than we did. ${ }^{24}$ In that series, however, there were more patients with occlusion at the carotid siphon. Patient 8 of our series, despite recanalisation, had a poor outcome. In this case the time elapsed from stroke to treatment was 300 minutes, and this might have been crucial together with the pulmonary oedema from cardiac failure that occurred the next day. Intraparenchymal cerebral haematoma was seen in one patient. In two other patients with a haemorrhage it was clinically silent and not necessarily related to treatment as haemorrage as well as parenchymal haematoma can be part of the natural history of ischaemic stroke. ${ }^{25}$ Two patients with basilar stroke had the worst outcomes (death and locked in syndrome). These were associated with persistent occlusion in one and reocclusion of the partially recanalised trunk in the other. Both were probably of atherothrombotic origin, as was the case with middle cerebral artery occlusion described by Jungreis et $a l^{26}$ and treated in the same way. Two patients 
with persistent recanalisation after basilar artery occlusion became independent, and it has to be considered an excellent outcome in this vascular syndrome, in which the prognosis is poor. ${ }^{27}$ Our experience has to be considered anecdotal, due to the few patients and the absence of a randomised control group, which precluded statistical analysis. We are contemporaneously involved in a joint clinical trial with an intravenous approach for patients with carotid artery stroke, with broader age limits and without requirement for angiography. Less than 20 of the patients included in those trials could be treated with an intra-arterial approach according to our criteria. If these were included the numbers would still be very small. A large trial would certainly be advisable, but would be costly, with requirement of a great number of centres selecting among thousands of patients. ${ }^{28}$ Objections might then be raised after an angiography not followed by any treatment after showing the appropriate occlusion.

With these limitations, we think that this approach can be a therapeutic option in the treatment of acute ischaemic stroke, possibly integrated in the future with new diagnostic tools able to give further information in the very early stages. ${ }^{29-30}$ It has to be remembered that conventional CT is still a reliable tool in the hyperacute setting of a stroke. ${ }^{31}$ The importance of a quick referral of the selected patient, evaluation by trained neurologists, and rapid access to neuroradiological facilities staffed by a skilled interventional team must be stressed.

\section{Addendum}

By the time this paper was completed, the results of the trial with intravenous tissue plasminogen activator in acute ischaemic stroke had been published. ${ }^{32}$ The conclusions are that treatment within three hours of the onset of acute ischaemic stroke improves clinical outcome at three months. The selection made, with inclusion of patients with a broad range of neurological deficits and stroke subtypes not angiographically proved, while giving a more optimistic view on intravenous thrombolysis, does not lessen in our opinion the validity of the intra-arterial approach in particularly defined cases.

1 del Zoppo JG. Thrombolytic therapy in acute stroke, recent experience. Cerebrovasc Dis 1993;3:256-63.

2 Wardlaw JM, Warlaw CP. Thrombolysis in acute ischemic stroke: does it work? Stroke 1992;23:1826-39.

3 Brott T, Broderick J, Kothari R. Thrombolytic therapy for stroke. Current opinion in Neurology 1994;7:25-35.

4 Hacke W, Kaste M, Fieschi C, et al. Intravenous thrombolysis with recombinant tissue plasminogen activator for acute hemispheric stroke: the European Cooperative Acute Stroke Study (ECASS). $\mathcal{J} A M A$ 1995;274: 1017-25.
5 Casto L, Moschini L, Camerlingo M, et al. Local intraarterial thrombolysis for acute ischemic stroke in the carotid rial thrombolysis for acute ischemic stroke in the caroti
artery territory. Acta Neurol Scand 1992;86:308-11.

6 Bozzao L, Bastianello S, Fantozzi CM, Angeloni V, Argentino C, Fieschi C. Correlation of angiographic and sequential CT findings in patients with evolving cerebra infarction. AfNR Am F Neuroradiol 1989;10:1215-22.

7 Brott T, Adams HP Jr, Olinger CP. Measurement of acute cerebral infarction: a clinical examination scale. Stroke 1989;20:864-70.

8 Bamford JM, Sandercock PAG, Warlow CP, Slattery J. Interobserver agreement for the assessment of handicap in stroke patients. Stroke 1989;20:828.

9 del Zoppo JG, Poek K, Pessin MS and the Acute stroke Study group. Recombinant tissue plasminogen activator in acute thrombotic and embolic stroke. Ann Neurol 1992;32:78-86.

10 Mori E, Yoneda Y, Tabuchi M, et al. Intravenous recombinant tissue plasminogen activator in acute carotid artery territory stroke. Neurology 1992;42:976-82.

11 Von Kummer R. Intravenous tissue plasminogen activator in acute stroke. In: Hacke W, del Zoppo JG, Hirchberg $\mathrm{M}$, eds. Thrombolytic therapy in acute ischemic stroke. Heidelberg: Springer, 1991;161-7.

12 Yamaguchi $\mathrm{T}$. Intravenous rtPA in acute embolic stroke. In: Hacke $W$, del Zoppo JG, Hirshberg $M$, eds. Thrombolytic therapy in acute ischemic stroke. Heidelberg: Springer, 1991:168-74

13 del Zoppo JG, Ferbert A, Otis S, et al. Local intraarterial fibrinolythic therapy in acute carotid territory stroke: a pilot study. Stroke 1988;19:307-13.

14 Mori E, Tabuchi M, Yoshida T, Yamadori A. Intracarotid urokinase with thromboembolic occlusion of the middle cerebral artery. Stroke 1988;19:802-12.

15 Zeumer H, Freitag HG, Grzyka U, Neunzig HP. Local intra arterial fibrinolysis in acute vertebrobasilar occlusion: technical developments and recent results. Nion: technical developments

16 Theron J, Courtheoux $\mathrm{P}$, Casasco A, et al. Local intraarterial fibrinolysis in the carotid territory $A \mathcal{F} N R \mathrm{Am} \mathcal{F}$ Neuroradiol 1989;10:753-65.

17 Matsumoto K, Satoh K. Topical intraarterial urokinase infusion for acute stroke. In: Hacke W, del Zoppo JG, Hirschberg M, eds. Thrombolytic therapy in acute ischemic stroke. Heidelberg: Springer, 1991:207-12.

18 del Zoppo JG, Zeumer H, Harker LA. Thrombolytic therapy in acute stroke: possibilities and hazards. Stroke 1986;17: 595-607.

19 Mori E. Fibrinolytic recanalization therapy in acute cerebrovascular thromboembolism. In: Hacke W, del Zoppo JG, Hirschberg $\mathrm{M}$, eds. Thrombolytic therapy in acute ischemic stroke. Berlin: Springer Verlag, 1990:137-46.

20 Caplan LR. Brain embolism revisited. Neurology 1993;43: 1281-7.

21 Ito Z, Suzuki A, Menura K. Prognostic factors in spontaneous recanalization of middle cerebral artery occlusion. In: Ito Z, Kutzuzawa T, Yasui N, eds. Cerebral ischemiaan update. Amsterdam: Excerpta Medica, 1983:159-66

22 del Zoppo GJ, Pessin MS, Mori E, Hacke W. Thrombolytic therapy in acute thrombotic and embolic stroke. Semin Neurol 1991;11:368-84.

23 Von Kummer R. Intraarterial fibrinolysis in intracranial artery occlusion. In: Bozzao L, ed. Neuroradiologia Udine: Ed del Centauro, 1995:179-82.

24 Bollaert PE, Bracard S, Boulanger T, et al. Early local intraarterial thrombolysis for severe middle cerebral artery stroke. Cerebrovasc Dis 1995;5:292-6.

25 Hornig CR, Dorndorf W, Agnoli A. Hemorrhagic cerebral infarction-a prospective study. Stroke 1986;17:179-85.

26 Jungreis CA, Wechsler RR, Horton J. Intraarterial thrombolysis with a catheter embedded in the clot. Stroke 1989; 20:1578-80.

27 Hacke W, Zeumer H, Ferbert A, Brukmann H, del Zoppo JG. Intraarterial thrombolysis improves outcome in patients with acute vertebrobasilar occlusive disease. Stroke 1988;19:1216-2

28 Ferguson RDG, Ferguson JG. Cerebrebral intraarterial fibrinolysis at the crossroads: is a phase III trial advisable at this time? AfNR Am $\mathcal{f}$ Neuroradiol 1994;15:1201-16.

29 Warach S, Chien D, Li W, Ronthal M, Edelmann RR. Fast magnetic resonance diffusion weighted imaging of acute human stroke. Neurology 1992;42:1717-23.

30 Rother J, Guckel F, Neff W, Kuhnen J, Hennerici M, Schwartz A. Assessment of cerebral blood volume in acute stroke using dynamic contrast enhanced magnetic resonance imaging. Neurology 1994;44 (suppl 2):182A.

31 Mohr J, Biller J, Hilal SK, Yiu WTC, Tatemichi TK. Magnetic resonance versus computed tomographic imaging in acute stroke. Stroke 1995;26:807-12.

32 The National Institute Of Neurological Disorders and Stroke rt-PA Stroke Study Group. Tissue plasminogen Stroke rt-PA Stroke Study Group. Tissue plasminogen
activator for acute ischemic stroke. N Engl $\ngtr$ Med 1995; 333:1581-7. 